\title{
Tilføjelse af DOI i forbindelse med QuickSubmit Plugin
}

Når man, i forbindelse med publicering på OJS, anvender Quick Submit Plugin er det vigtigt, at man efter brugen af denne plugin selv aktivt tilføjer artiklens DOI. Dette sker ikke automatisk, som tilfældet er når man anvender programmets eget redaktionelle workflow.

\section{Sådan tilføjes DOI}

Gå ind under 'Numre' > 'Fremtidige numre'. Klik på den blå trekant ud for det pågældende nummer og vælg dernæst linket 'Redigér'.

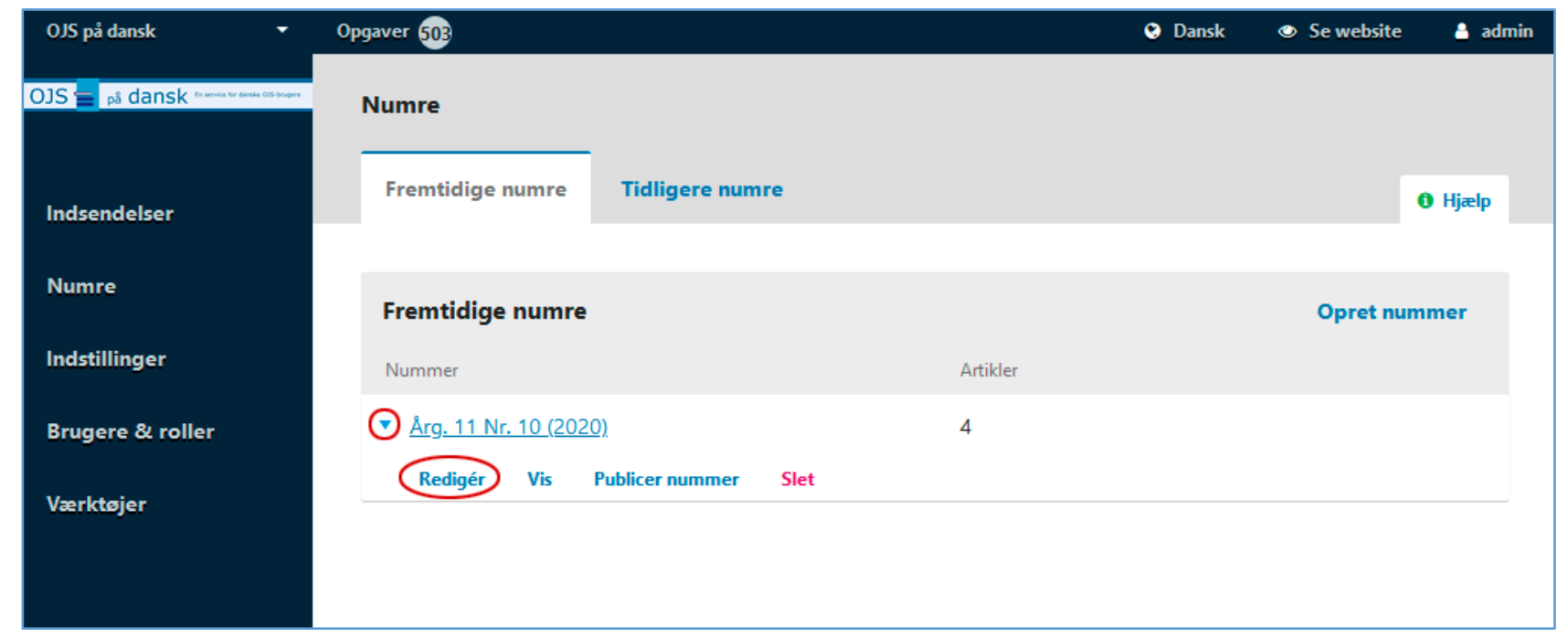

Klik dernæst igen på den blå trekant - nu ud for den aktuelle artikel - og vælg linket 'Indsendelse'

\section{Vejledninger}

- Sådan publicerer du html-filer, der indeholder billeder, i OJS 3

- How to publish XML files containing images in OJS 3

(-) Brug af iframe-tag i html-filer til OJS under tidsskrift.dk

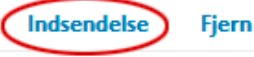

- Abonnementsopsætning 
Herved kommer artiklens produktionsside med adgang til metadata frem. Klik på linket 'Metadata'

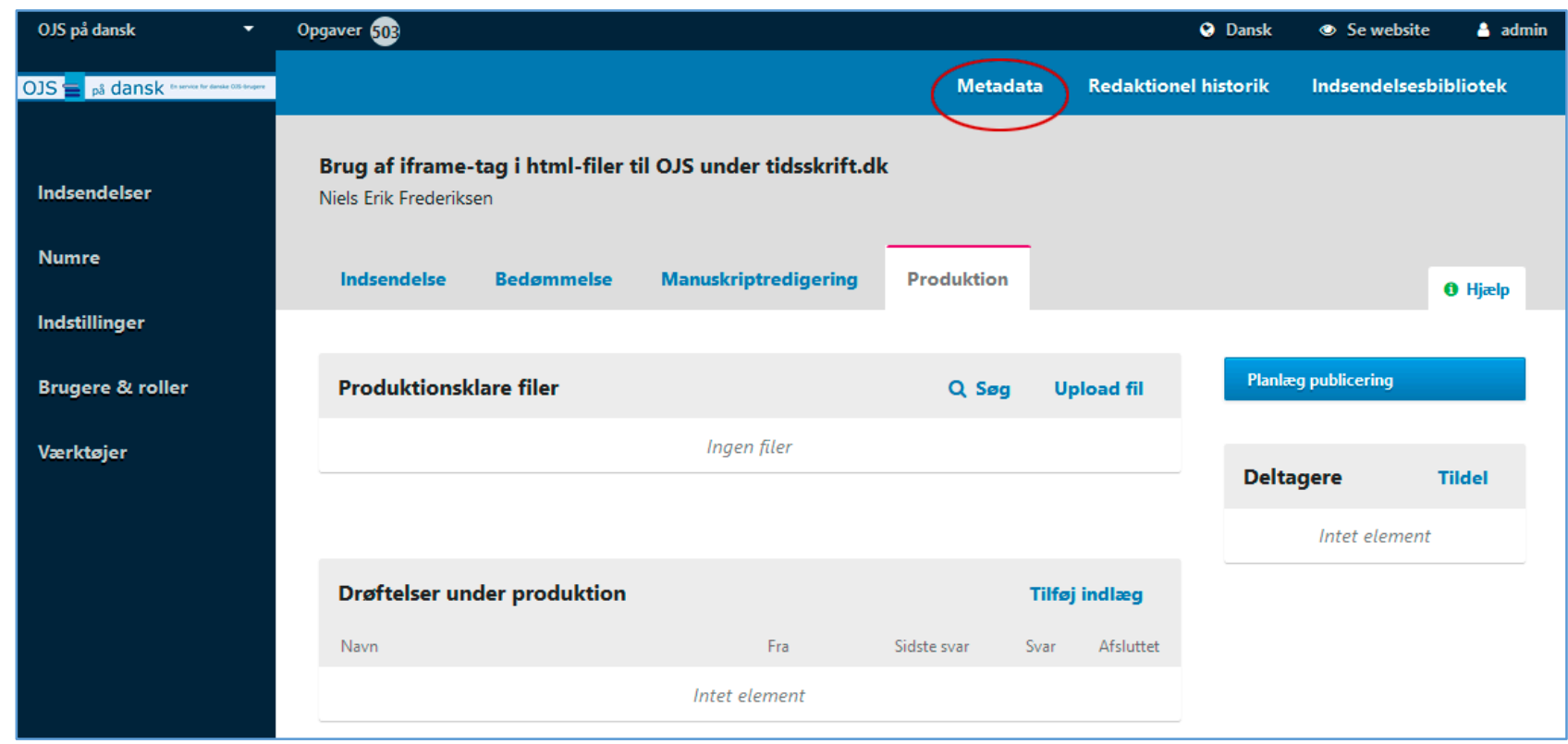

I metadatavinduet vælges 'Identifikator'

Indsendelses- og publikationsmetadata

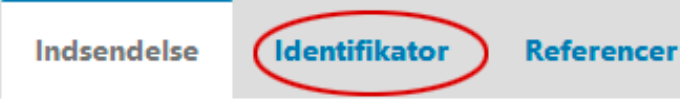

\section{Sektion *}

Vejledninger

Vœlg den relevante sektion til dette manuskript *

\section{Sprog}

Dansk

Dette tidsskrift accepterer indleverede manuskripter på en række sprog. Valg det primare sprog for indleveringen $i$

rullemenuen. *

Præfiks

Titel *

Eksempler: $A$, The

\section{Undertitel}

Med en indlejret pdf-fil

Undertitlen kan eventuelt indskrives med et kolon indsat efter hovedtitlen. 
Som det fremgår ses en forhåndsvisning af artiklens DOI. For at tilføje denne DOI til artiklen skal man klikke på Gem-knappen.

Indsendelses- og publikationsmetadata

\section{Public URL identifier}

\section{DOI}

10.7146/ojssb.v11i10.121191

Dette er en forhåndsvisning af DOI. Vælg afkrydsningsfeltet og gem formularen for at tilføje DOI.

$\square$ Tilføj DOI til artikel

Gem Annuller

Nu er DOI’en tilføjet og artiklen kan publiceres.

Indsendelses- og publikationsmetadata

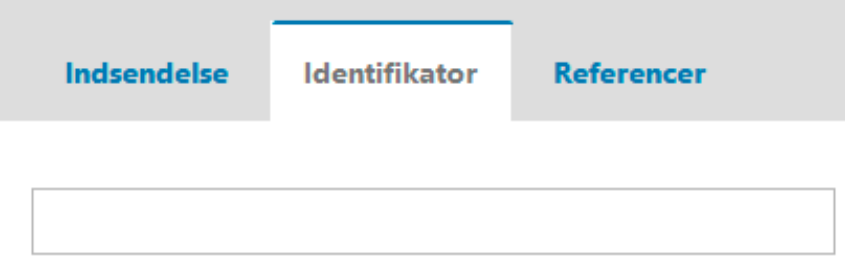

Public URL identifier

DOI

10.7146/ojssb.v11i10.121191

DOI er tilføjet artikel.

Fjern DOI

Gem Annuller 